\title{
Research on the Performance Evaluation System of Professional Laboratories in Chinese National Universities
}

\author{
Zhitan Feng ${ }^{1,}$ a, Yan $\mathrm{Li}^{1}$, Qianqian $\mathrm{Su}^{2}$ \\ ${ }^{1}$ School of commercial, Nantong Institute of Technology, Nan Tong 226002, China \\ ${ }^{2}$ Social public service department, Jiuzhou Polytechnic, Xu Zhou, 221000, China \\ aFengzhtan@126.com
}

\begin{abstract}
The construction and improvement of laboratories in private universities is an important channel and place for improving students' skill level, and an important construction requirement for applied undergraduate colleges. Only when there are enough laboratory construction conditions can students' practical ability be fully improved. The laboratory construction involves the use of funds, laboratory operations, and student experiment results. Firstly, this paper analyzes the shortcomings of private colleges and universities in the construction of laboratories, and finds out the reasons. Based on the relevant literature and the professional characteristics of economy and management, this paper establishes a private enterprise with the aim of training applied talents. The university laboratory performance evaluation system has established a two-tiered indicator system. The indicator system has three levels of indicators: laboratory comprehensive output capacity, laboratory management and service level, and comprehensive utilization level of laboratory assets. Each indicator contains multiple secondary indicators, and a total of three levels are constructed. A two-level performance evaluation index system, the construction of these indicator systems provides strong support for the construction and development of private college laboratories.
\end{abstract}

Keywords: private colleges; laboratory; performance evaluation system.

\section{Introduction}

China's economic development has been upgraded from high-speed to high-quality development. Most of the private undergraduate colleges have shifted to application-oriented. Private higher vocational colleges aim to cultivate high-skilled talents. Laboratory construction is an important place for students to improve their skills and familiarize themselves with the working environment. It is an important platform for teaching, research and practice. The construction of the laboratory provides an important way for private colleges and universities to upgrade the talent level, improve the ability of talents to adapt to the society, and realize the goal of training talents. Through laboratory knowledge, it is important to establish the characteristics of school and professional characteristics. However, as a private college, because of its lack of government support, mainly from its own investment and tuition income, how to measure the performance level of the laboratory, how to make the situation of limited funds, through the cooperation of schools, enterprises and the government To make the laboratory play the most important role, making it an important topic in the construction of laboratories in private universities. The construction of laboratory performance evaluation system provides an important reference for laboratory construction, avoiding qualitative and artificial assessment methods, so that the overall response laboratory can be used to clear, timely find problems and solve problems, and improve laboratory output level and efficiency.

\section{Analysis of the Status Quo of Laboratory Construction in Private Colleges}

Through the investigation and analysis of the laboratories of private universities in Jiangsu Province, although the majority of private colleges and universities through their own investment and construction, the overall structure of the laboratory is relatively perfect. However, there are still many problems and gaps in the construction of various professional talents in the laboratory. It is unable to meet the needs of professional construction. The overall performance appraisal system has not been established, and the output is low, forming a state level that only meets basic needs. Especially in the economics and management professions, most of the professional construction of capital investment 
and computer investment, software investment is not enough, can not meet the needs of high-skilled talents. Based on the investigation and research of private colleges and universities in Jiangsu Province, this paper summarizes the main problems existing in the development and construction of private laboratory in the laboratory, and analyzes the related reasons, which is the performance evaluation system of the laboratory. The establishment provides goals and meaning. The main problems and causes are mainly the following aspects.

\subsection{The Lack of Master Plan for Laboratory Construction}

Due to the short construction time of private colleges and universities, there is no government financial support, and the accumulation of self-owned funds is mainly accumulated. As a result, the laboratory construction in the school has not been effectively integrated and optimized. The laboratories are independent of each other and lack overall and overall awareness. The new laboratory construction lacks the necessary arguments and detailed investigations, lacks a feasibility study report, and the bidding mechanism flows in form. Some laboratories are rushed to launch only in case of urgent need. After the completion of construction, the utilization rate is low, and it is unable to meet the requirements of professional development. In addition, there are multi-head management, laboratory management personnel are confused, and some have no special laboratory management personnel. The management is not standardized, which affects the overall performance level of the laboratory.

\subsection{Insufficient Capital Investment, Insufficient Cultural Construction}

The college's investment in student experiments has increased every year. In particular, the growth rate of undergraduate colleges is higher than that of applied colleges. Many university laboratories have both scale and characteristics. As private colleges, due to a single source of funds, the overall investment is insufficient. Unbalanced investment between majors has seriously restricted the construction of laboratories and the benefits of private universities. As far as the current well-built laboratories are concerned, the cultural construction is backward, the atmosphere is not enough, and the connotation construction is seriously inadequate. In terms of economics and management, it is even more so. Just a few posters are displayed, and the computer and table display have no features. Introduction, development history, and so on.

\subsection{Excellent Experimental Instructors Lack Resources}

On the one hand, the lack of laboratory personnel is a normal state in private university laboratories; on the other hand, the number of teaching staff in the laboratory is mainly young teachers, many graduates directly from colleges and universities, the structure of teachers is out of balance, and the full-time teachers are especially There are serious shortages of teachers with front-line work managers. This poses great difficulties for the cultivation of talents in applied universities. Because these teachers lack practical experience, they often do not follow the same principles. By visiting schools, teachers, and students, everyone recognizes that experimental class teachers should strengthen their practical ability, strengthen research in laboratory construction and professional training, and actively participate in various types of training. Can be better played.

\subsection{Lack of Laboratory Management System}

There is a lack of management personnel in the laboratory management system of private universities, lack of necessary management measures and means, although the security management has been strengthened, but the system is still not enough. In particular, after problems such as computers and other instruments, managers push each other, communication and coordination are not smooth, and professionals are lacking. Often, the resolution of a problem needs to be solved by multiple departments and it takes many days. The laboratory management evaluation is only based on post-evaluation. Lord, prior analysis, less control in the matter. 


\subsection{School-enterprise Co-construction Laboratory Lacks}

School-enterprise integration is one of the important ways to establish laboratories in private universities. However, there are still many problems in actual construction and operation. On the one hand, the enthusiasm of the school is very great. Many schools have established school-enterprise cooperation departments, and also introduced enterprise personnel to serve as deputy deans of the second-level colleges. However, many forms are larger than the essence, especially the laboratories funded by enterprises involve students in employment. Wages and income distribution issues, etc., have a lot of impact on the construction and development of school-enterprise co-construction laboratories. There are often schools and enterprises that have their own evidences, different goals, and different ways, resulting in minimal results. The construction of the laboratory should reflect the characteristics of sharing and service. After the construction of the laboratory, it plays a minor role in undertaking social training and technical services, and does not produce relevant social benefits. The operation of new training modes such as school factories and modern apprenticeships. The results require further evaluation. The overall social value output of the laboratory is very limited, and the laboratory has only become a classroom teaching place, and there is no multi-party interaction mechanism.

\section{Construction of Laboratory Performance Evaluation Index System in Academic Institutions}

The construction of laboratories in private universities must first carry out laboratory construction according to their own development level and positioning. After the completion of laboratory construction, it is necessary to evaluate and analyze their performance in order to further improve the level of laboratory construction. In the process of constructing the laboratory performance evaluation index system, it is necessary to combine not only the school's own situation, but also the professional development, especially the key professional construction, professional characteristics and needs, the difficulty of cooperation between schools and enterprises, etc. In the formation of professional features. At the same time, the construction of the indicator system should be scientific and reasonable, and try to use quantitative indicators to facilitate the evaluation and analysis between schools and departments.

\subsection{Performance Evaluation System of Campus Labor in Private Colleges and Universities}

With reference to the research on the performance evaluation indicators of domestic and foreign laboratories, combined with the characteristics of private colleges and universities, the selection of index system is based on the training of applied talents, and establishes the performance evaluation system of private colleges and universities with the aim of applying talents. A two-tiered indicator system. The indicator system has three levels of indicators: comprehensive utilization of laboratory assets, comprehensive laboratory output capacity, laboratory management and service level. Each indicator contains multiple secondary indicators, and a total of three levels are constructed. A twolevel performance evaluation index system, the construction of these indicator systems provides strong support for the construction and development of private college laboratories. The construction of the laboratory performance evaluation system needs to first clarify the connotation of each indicator in order to better carry out quantitative analysis and evaluation.

The following 15 indicators of the two-level indicator system screened are explained and explained.

(1) Comprehensive utilization level of laboratory assets.

Private colleges and universities, especially with the application of talents as the target, are experimental training activities. In terms of the comprehensive utilization level of laboratory assets, it is mainly necessary to consider the laboratory utilization rate, the opening rate, the equipment integrity rate and the student participation rate during the period., where equipment utilization refers to the ratio between the number of hours of use of the laboratory in a calculation cycle and the total number of hours that the laboratory can provide, reflecting the actual operation of the laboratory, based on the schedule data, especially the laboratory registration manual. Statistics and acquisition. 
The laboratory opening rate emphasizes whether the laboratory opening plan is consistent with the objectives and content of the laboratory construction. The equipment integrity rate needs to be deducted from the use of daily consumables, and the integrity of the equipment at the beginning and after use of the equipment is investigated. The student participation rate is an indicator that reflects the degree of student participation by calculating the ratio of the number of students participating in the laboratory to the number of students.

(2) Laboratory comprehensive output capacity.

The comprehensive output capacity of the laboratory mainly examines the main output capacity and level of the laboratory in the operation process, mainly through the number of key laboratories (number of topics), teacher and student satisfaction levels, business satisfaction and incomegenerating capacity, and laboratory sharing level. Indicators such as innovative innovations. The number of key laboratories needs to be evaluated and approved in the school. The satisfaction of teachers and students can be obtained through regular survey data. The satisfaction of enterprises mainly investigates the ability of enterprises to recognize the skills of students. If enterprises participate in construction, they need to investigate the establishment of enterprises. The degree of achievement of the training room goal, income-generating ability is to investigate the income of the laboratory in addition to the teaching tasks. The sharing level of the laboratory examines whether a laboratory can provide experimental support and cooperation between different professions and even different schools. The iconic innovation results refer to innovative and iconic achievements in training room management reform, student talent training and mechanism operation.

(3) Laboratory management and service level

The level of laboratory performance evaluation is closely related to laboratory management and service level. On the one hand, laboratory construction is inseparable from the investment of school funds. On the other hand, laboratories need to establish more comprehensive laboratory rules and regulations and safety management systems. Laboratory management and service level design laboratory system management, laboratory safety management, laboratory daily operation management, laboratory culture management and laboratory personnel management.

\subsection{Characteristics of the Performance Evaluation Index System of the Laboratory in the School}

By investigating the status quo of private university laboratory construction and domestic and foreign reference literature, we have constructed three first-level indicators and 15 secondary indicator systems. The construction of these indicators has several advantages:

(1) The laboratory performance evaluation system integrates the general indicators of laboratory evaluation, and also adjusts the development of private universities, focusing on school-enterprise cooperation and laboratory operation and management. Due to the limited funds of private colleges and universities and limited teachers, it is necessary to consider the income level and sharing that the laboratory can bring in order to comprehensively improve the sustainable development level of the laboratory and improve the overall level.

(2) The laboratory evaluation system introduces student satisfaction, introduces student training into the laboratory construction, determines that the laboratory construction and development must be student-centered, and cultivate students' applied high-skilled talents as the training goal and improve the student society. Adaptability, strengthen students' ability of innovation and entrepreneurship, thereby further promoting professional development, forming a special specialty, brand professional, and professional development also promotes further improvement and improvement of the laboratory.

\section{Summary}

The laboratory is an important place for the implementation of practical teaching links in applied colleges. The construction of experimental bases for students to receive practical training and experience and experience is an important part of the practical teaching system of applied colleges. 
The important part of the basic construction of education and teaching is an important way to highlight the characteristics of running a school and improve the quality of teaching. It is the basic guarantee for improving students' professional skills, cultivating professional ability and improving professional quality, and cultivating high-quality talents. The difference between private colleges and public colleges is different in terms of the main body of running schools, sources of funds, system of running schools, and scale of running schools. The construction and management of experimental bases are mainly carried out through self-raising, with little financial support. For the college, in the period of rapid economic development and limited investment in the construction of the college, how to evaluate the performance and management of the training base in the school to ensure the rational use of the investment in the training room and maximize the benefits is a private application hospital. An important topic in the construction of the school training room. Firstly, this paper analyzes the shortcomings of private colleges and universities in the construction of laboratories, and finds out the reasons. Based on the relevant literature and the professional characteristics of economy and management, this paper establishes a private enterprise with the aim of training applied talents. The university laboratory performance evaluation system has established a two-tiered indicator system. The indicator system has three levels of indicators: laboratory comprehensive output capacity, laboratory management and service level, and comprehensive utilization level of laboratory assets. Each indicator contains multiple secondary indicators, and a total of three levels are constructed. A two-level performance evaluation index system, the construction of these indicator systems provides strong support for the construction and development of private college laboratories.

\section{Acknowledgments}

First Level Key Built Discipline Projects of the Business Administration under Jiangsu Provincial "the 13th Five-Year Plan". Project number: SJY201609; Nantong Institute of Technology professor and doctoral research project (201823).

\section{References}

[1]. Wang Binnan, Chen Jianxin, Gong Shiwen, Hu Weishi, Su Xing. Research on the Improvement of University Laboratory Safety Management Level under the Performance Management Theory[J].Experimental Technology and Management, 2019,36(06):259-262+266.

[2]. Zhang Yang, Chen Yizhen. Research on the Performance Evaluation of Applied Undergraduate University Based on Fuzzy Analytic Hierarchy Process[J]. Light Industry Technology, 2019, 35(01):120-123.

[3]. Zhang Dafu, Ren Xiaoyu, Wang Yinxing. Research on Performance Evaluation of Teaching Laboratory in Colleges and Universities[J]. Quality Education in the West, 2018, 4(24): 174+183.

[4]. ZHAO Yuyu, WANG Biqin, Yang Yuke, Tang Yuyue, Yuan Lijuan. Study on Innovation Performance Evaluation of Applied Laboratories in Applied Universities[J]. Experimental Technology and Management,2018,35(09):34-39.

[5]. Su Qianqian. Exploring the problems existing in the operation room of the training roomTaking the Kyushu Vocational and Technical College as an example [J]. Chinese Journal of Multimedia and Network Teaching (mid-term), 2018(04): 23-24.

[6]. Su Qianqian. Preliminary Study on the Performance Evaluation System of the Training Room Construction in Higher Vocational Colleges__ Taking the Music Training Room of J College as an Example[J].SME Management and Technology,2016(11):155- 156. 